\title{
TRIBOLOGICAL EVALUATION OF INTAKE VALVE AND VALVE SEAT OF A DIESEL CYCLE ENGINE IN REAL OPERATING CONDITIONS
}

\author{
Luciano T. B. Penhalbel ${ }^{1}$ and Marina Fuser Pillis ${ }^{2}$ \\ ${ }^{1}$ MWM Motores Diesel \\ ${ }^{2}$ IPEN - Instituto de Pesquisas Energéticas e Nucleares \\ E-mails: luciano.tadeu@navistar.com.br, mfpillis@ipen.br
}

\begin{abstract}
Automotive industry demands products that work under extreme conditions. The development of components for internal combustion engines is an action to improve this product, so that it reaches the required life with acceptable levels of wear and respecting the legal operating limits, such as values of emission pollutants. In view of these requirements, it is necessary to study components considered critical, which are known to influence the performance of the engine. So, within this universe the tribology of the intake valve and valve seat insert is an important set, that must receive attention to its wear and consequently its influence on the engine degradation, in the emission of pollutants and performance related to the operational maintenance requirements and life of the product. The aim of this work is to evaluate the behavior of the tribological intake pair, valve and valve seat insert, submitted to dynamometer and vehicular tests (real operating conditions), regarding the level and type of wear occurred in the pair. Correlating the results obtained with legal and operational performance requirements of a Diesel cycle engine, as well as the characterization of the wear type occurred in the tribological pair, with the related literature.
\end{abstract}

\section{INTRODUCTION}

Engines downsizing and greater specific efficiency are a strong trend of the automotive industry. This is basically due to the need of reducing vehicle mass, in order to reduce emissions of pollutants and fuel consumption. This fact makes necessary the use lighter of materials which are also resistant to extreme working conditions, mainly due to the increase of combustion pressures.

Valves and valve seats, for any type of engine, Diesel or Otto cycle, have the function of sealing the combustion chamber, in order to allow the necessary pressure for the combustion to be reached. Therefore, these components are very important for a clean burning with low pollutant emission rates.

Excessive wear of the intake valve and valve seat cause changes in engine combustion parameters, leading to decreased performance and changes in pollutant emission values [1]. In Brazil, as in other parts of the world, there are studies and applications of valve seat made by powder metallurgy, with the intention of bringing both the commercial aspect related to cost reduction [2] and the technical aspect related to better tribological compatibility [3]. 
There are few technical publications under real operating conditions related to the tribological valve and valve seat, especially for the intake pair. This work intends to fill this gap with practical information on the behavior of this pair.

The aim of this work is to evaluate the behavior of the tribological pair, valve and valve seat, submitted to dynamometer and vehicular tests (real operating conditions), regarding the level and type of wear occurred in the pair. The results obtained were correlated with legal and operational performance requirements of a Diesel cycle engine, as well as the type of wear occurring in the tribological pair, with the related literature.

\section{FUNDAMENTAL CONCEPTS}

\subsection{Valves and Valve seats}

Internal combustion engine valves work in extreme conditions, with high temperatures and high working pressures. In addition, this component must present a great dimensional accuracy. The valve can be divided into three areas: the tip end, the stem and the valve head. The tip end is the contact to either a finger follower or a tappet, depending on the element which is actuating the valve. The valve stem is guided in the cylinder head and transfers the heat. The valve head closes the opening in the cylinder head. FIG. 1 gives an overview of specific requirements and characteristics for each area of the valve. [1].

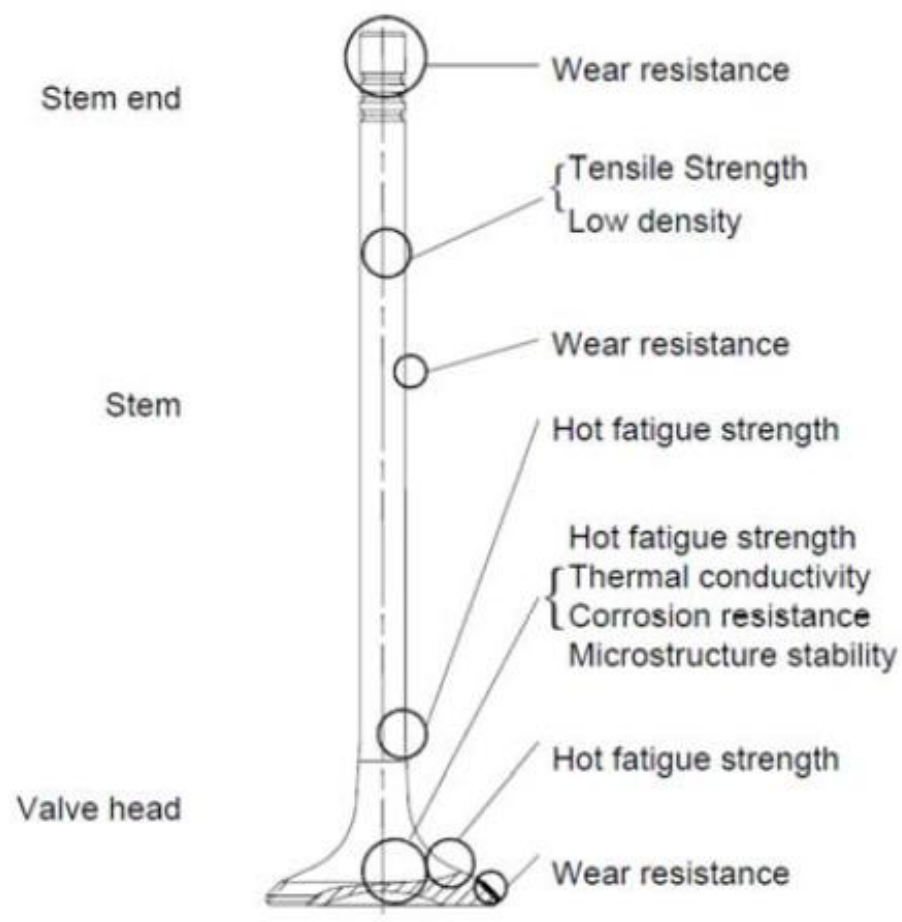

FIGURE 1: Characteristics and requirements of valve regions [4].

The valve seats are important components within the valve train system, being essential for perfect ignition and combustion inside the cylinder. Together with the 
valve this component must ensure complete sealing of the combustion chamber for the required compression and combustion pressures [1].

Valve seat insert materials must exhibit certain properties to satisfy the material technology requirements. The key properties are [1]: hot hardness, structural thermal stability, coefficient of thermal expansion, thermal conductivity, density, resistance to oxidation and corrosion, wear resistance, and machinability. FIG. 2 shows a valve seat applied to internal combustion engines.

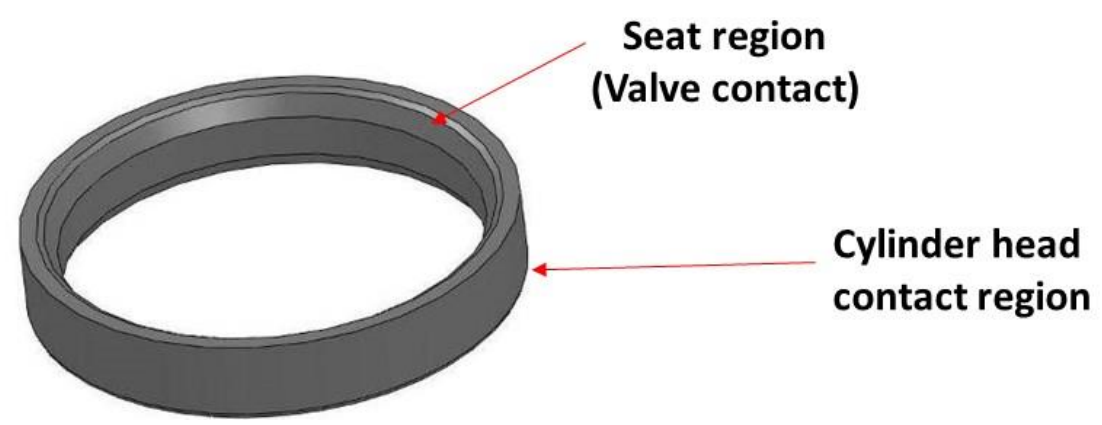

FIGURE 2: Three-dimensional figure of a MWM valve seat.

\subsection{Tribology}

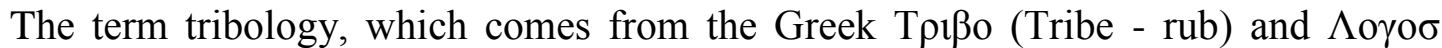
(Logos - study) was officially used for the first time in 1966 in a report made by $\mathrm{H}$. Peter Jost to the department committee English of education and science [5]. In this report, the term was defined as the "science and technology of interactive surfaces in relative movement and related subjects and practices" [6].

Tribology, which encompasses friction, wear and lubrication between surfaces in relative motion, is a new field of science defined in 1967 by a commission of the Organization for Economic Cooperation and Development [7].

Wear can be defined as the progressive loss of surface material under normal load and relative movement, which generally leads to surface degradation, loss of component function, and in some situations to catastrophic failure [8].

TAB. 1 compares the influence of fuel types and wear between valve and valve seat. In addition to these effects, lubricating oils can reach the contact area in the valve seat through the valve stem seal. Oil spill rates of $0.007-0.1 \mathrm{~cm}^{3} / 10 \mathrm{~h}$ are considered normal values during operation. 
TABLE 1: Influence of fuel type on wear action of tribological valve and valve seat. The evaluation of the intake and exhaust refers to lubrication of the valve couple and valve seat in a qualitative way.

\begin{tabular}{l|l|l|l|l|l} 
Fuel & Wear rate & $\begin{array}{l}\text { Intake set } \\
\text { evaluation }\end{array}$ & Intake Set & $\begin{array}{l}\text { Exhaust set } \\
\text { evaluation }\end{array}$ & Exhaust Set \\
\hline Gasoline & $1-5 \mu \mathrm{m} / 1000 \mathrm{~km}$ & ++ & Liquid lubrication & + & Solid lubrication \\
\hline Diesel & $1-5 \mu \mathrm{m} / 1000 \mathrm{~km}$ & - & No lubrication & ++ & Solid lubrication \\
\hline Alcohol & $1-10 \mu \mathrm{m} / 1000 \mathrm{~km}$ & $\circ$ & Liquid lubrication & $\circ$ & Liquid lubrication \\
\hline CNG & $2-50 \mu \mathrm{m} / 1000 \mathrm{~km}$ & -- & No lubrication & -- & No lubrication \\
\hline LPG & $20-70 \mu \mathrm{m} / 1000 \mathrm{~km}$ & -- & No lubrication & -- & No lubrication \\
\hline Hydrogen & $20-70 \mu \mathrm{m} / 1000 \mathrm{~km}$ & -- & No lubrication & -- & No lubrication \\
\hline
\end{tabular}

Evaluation: + + Very good, + Good, ${ }^{\circ}$ Medium, - Poor, - - Very poor.

Tribology between the valve and the valve seat must consider the following mechanisms for wear [9]:

- Metal removal: this is caused by (a) abrasives in the lubricant, (b) corrosion, (c) tearing away of high surface points; and (d) fatigue, which is commonly called "pitting" or "spalling".

- Metal transfer between surfaces, commonly called adhesion: this occurs with sliding and produces fusion contacting micropoints under high temperature, which sometimes also called welding, scoring, galling, and scuffing.

- Displacement of material by plastic flow, surface wear or staining: observed wear is a plastic deformation also known as wear under shear stress or radial flow, which involves a plastic deformation of the worn surface at the edge of the sliding direction due to the high stress of metal-to-metal contact and high friction at the interface.

All three forms of mechanisms for wear in the tribological pair valve and valve seat may occur at the same time. The FIG. 3 shows the parameters that can influence in valve and valve seat wear.

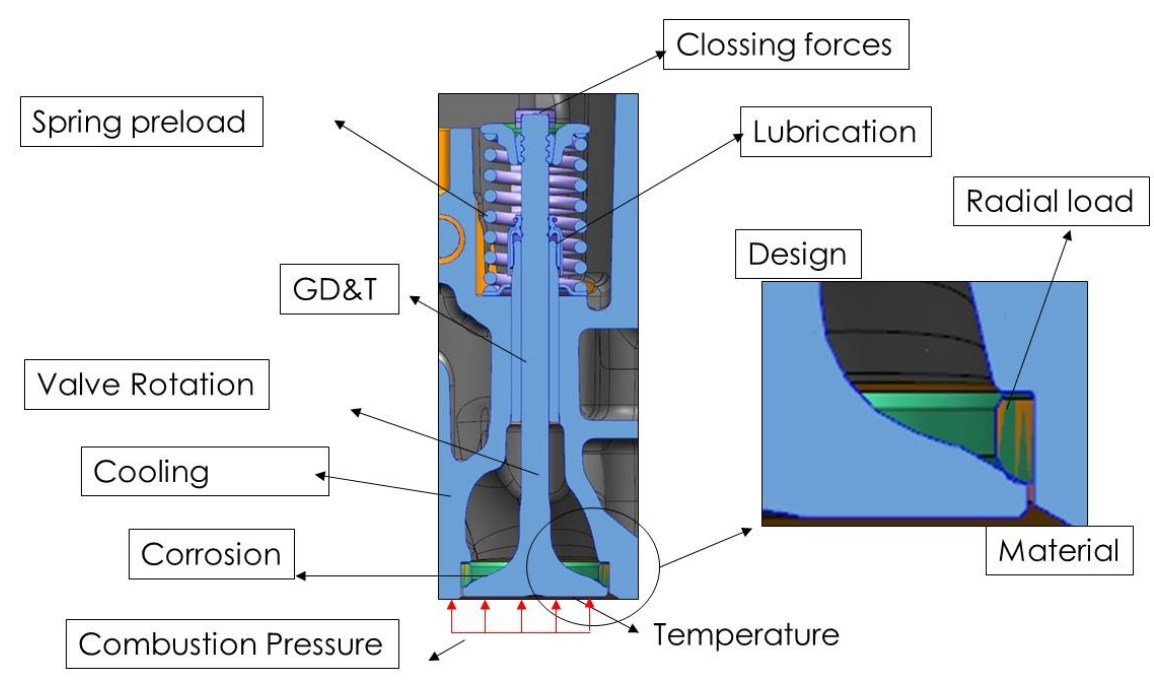

FIGURE 3: Tribological parameters related to valve and valve seat wear. Adapted from [1]. 


\section{MATERIALS AND METHODS}

2.1. Materials and dimensions

Intake valve and valve seat were used as received. The characteristics of material are:

\subsubsection{Valve}

- Material: Steel DIN EN 10090: 1998 - X85CrMoV18-2;

- Tensile strength: $1050 \mathrm{~N} / \mathrm{mm}^{2}$;

- Hardness: 45 HRC.

FIG. 4 shows the head diameter dimension of the valve:

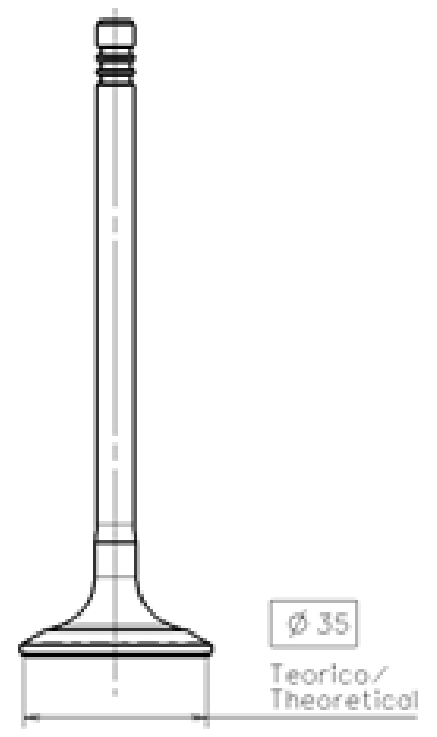

FIGURE 4: Main dimensions of the intake valve.

\subsubsection{Valve Seat}

The nominal chemical composition (\% by weight) is presented in TAB. 2 .

TABLE 2: Chemical composition of the valve seat (\% by weight).

\begin{tabular}{l|l|l|l|l|l|l|l|l|l|l|l|l} 
Element & $\mathrm{C}$ & $\mathrm{Co}$ & $\mathrm{Mo}$ & $\mathrm{W}$ & $\mathrm{V}$ & $\mathrm{Cr}$ & $\mathrm{Si}$ & $\mathrm{Mn}$ & $\mathrm{S}$ & $\mathrm{Cu}$ & Fe & $\begin{array}{l}\text { Others } \\
\text { Elements }\end{array}$ \\
\hline $\begin{array}{l}\text { Nominal } \\
\text { Value }\end{array}$ & $\mathbf{1 . 0 5}$ & $\mathbf{1 8 . 5}$ & $\mathbf{1 1 . 5}$ & $\mathbf{3 . 5}$ & $\mathbf{1 . 8}$ & $\mathbf{4 . 5}$ & $\mathbf{1 . 2 5}$ & $\mathbf{0 . 9}$ & $\mathbf{0 . 4 5}$ & $\mathbf{1 5 . 0}$ & Balance & $<3.0$
\end{tabular}

The valve seat is a fast sintered, microstructure steel consisting of fine carbides and intermetallic phases distributed uniformly in a tempered martensitic matrix. Solid lubricants are evenly distributed and the pores filled with copper. FIG. 5 shows the intake valve seat microstructure. 


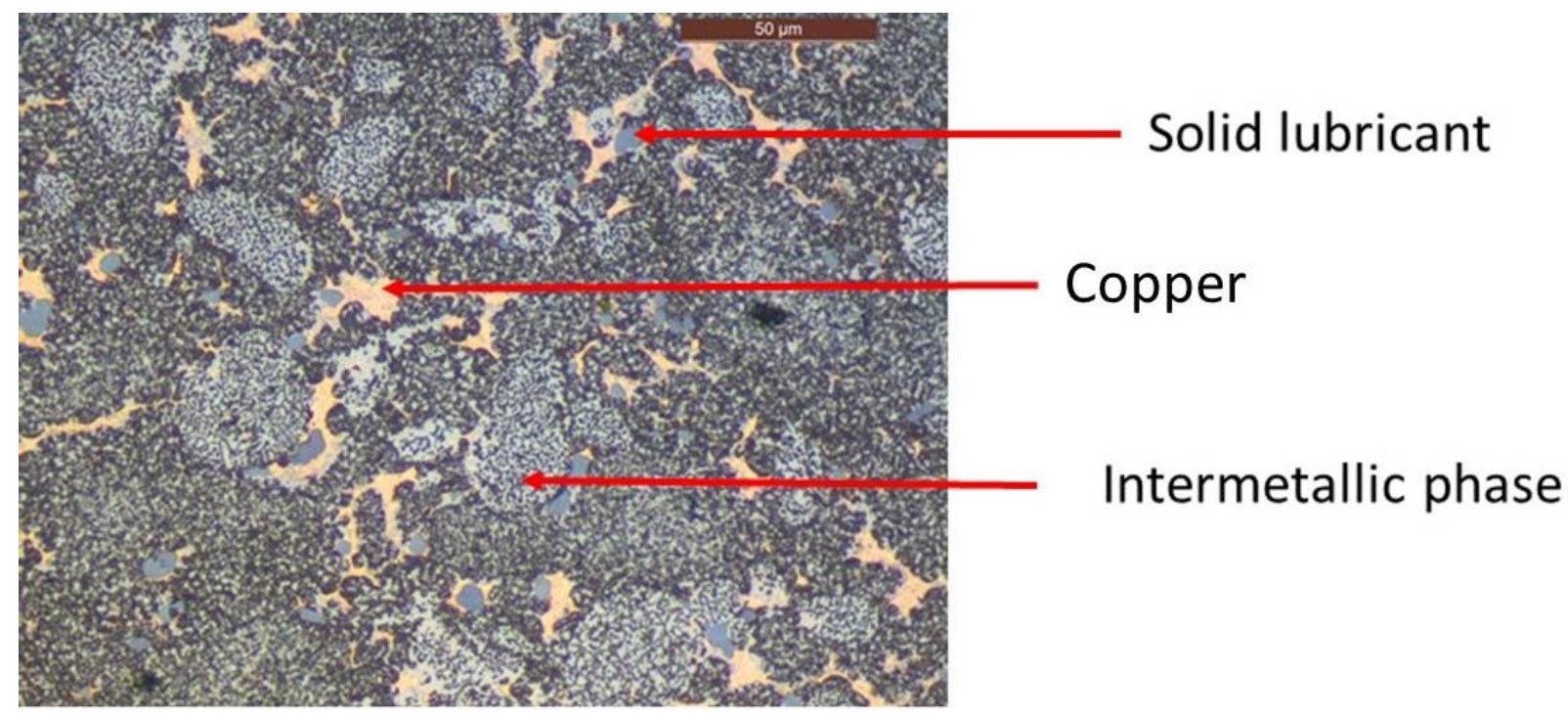

FIGURE 5: Optical microscope micrograph showing matrix structure - carbides distributed finely and uniformly, and an intermetallic phase in a martensitic matrix. Attack: Nital 3\%.

- Modulus of elasticity: $150000 \mathrm{MPa}$

- Hardness: 45 HRC

FIG. 6 shows the main dimensions of the valve seat, already mounted on the cylinder head. This mounting image was used because the seat is machined after mounted in cylinder head.
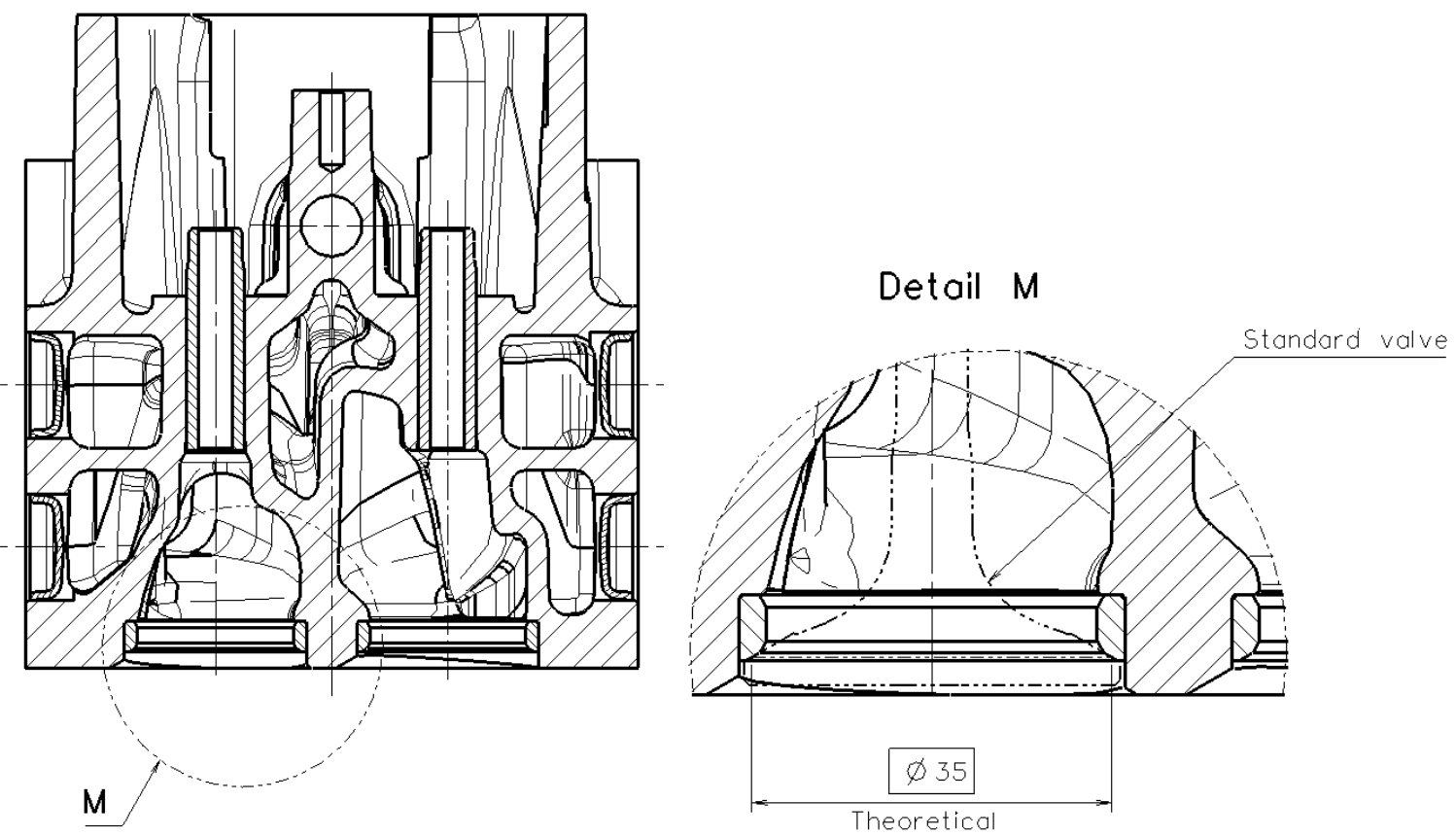

FIGURE 6: Main dimensions of the valve seat mounted on the head. It is worth noting that there are two intake valve seats per cylinder head. 


\subsection{Methods}

For the tests execution, engines with the following characteristics were used:

- Engine: Diesel turbo with cooling of the intake air;

- Total capacity: 7.2 liters;

- Power: $330 \mathrm{cv}$ at $2200 \mathrm{rpm}$;

- Combustion pressure: 180 bar in the 2200 rpm at full load engine condition;

- Nominal Torque: 1300 Nm (132.5 m.kgf) from $1200 \mathrm{rpm}$ up to $1600 \mathrm{rpm}$;

- Emission Level according to the standard: PROCONVE P7 / Euro V.

\subsubsection{Dynamometer and vehicle test}

The dynamometer durability test consisted of running the engine for 2000 hours, corresponding to $200,000 \mathrm{~km}$, according to the cycle described in the TAB. 3.

In the dynamometer were done the performance and emissions of pollutant according to CONAMA - PROCONVE 7 [10], before and after the 2000 - hour durability test. The behavior of the tribological pair was evaluated the level of wear occurred, as well as the type of wear. The vehicle durability test focused on the evaluation of the operational conditions related to the life and maintenance of the product.

TABLE 3: Durability test cycle.

\section{Dynamometer test cycle}

\begin{tabular}{c|l}
\hline Duration of test & $2000 \mathrm{~h}$ \\
\hline \multicolumn{2}{c}{ Cycle }
\end{tabular}

\begin{tabular}{c|c|c|c}
\hline Step & Engine Speed (rpm) & Load (\%) & Time (min) \\
\hline 1 & 1000 & 30 & 2 \\
\hline 2 & 2200 & 100 & 45 \\
\hline 3 & 1635 & 60 & 25 \\
\hline 4 & 1390 & 100 & 4 \\
\hline 6 & 2550 & 0 & 10 \\
\hline
\end{tabular}


The vehicle durability tests were conducted until the vehicle completed 100,000 km. Route data and vehicle characteristics are given in FIG. 7.

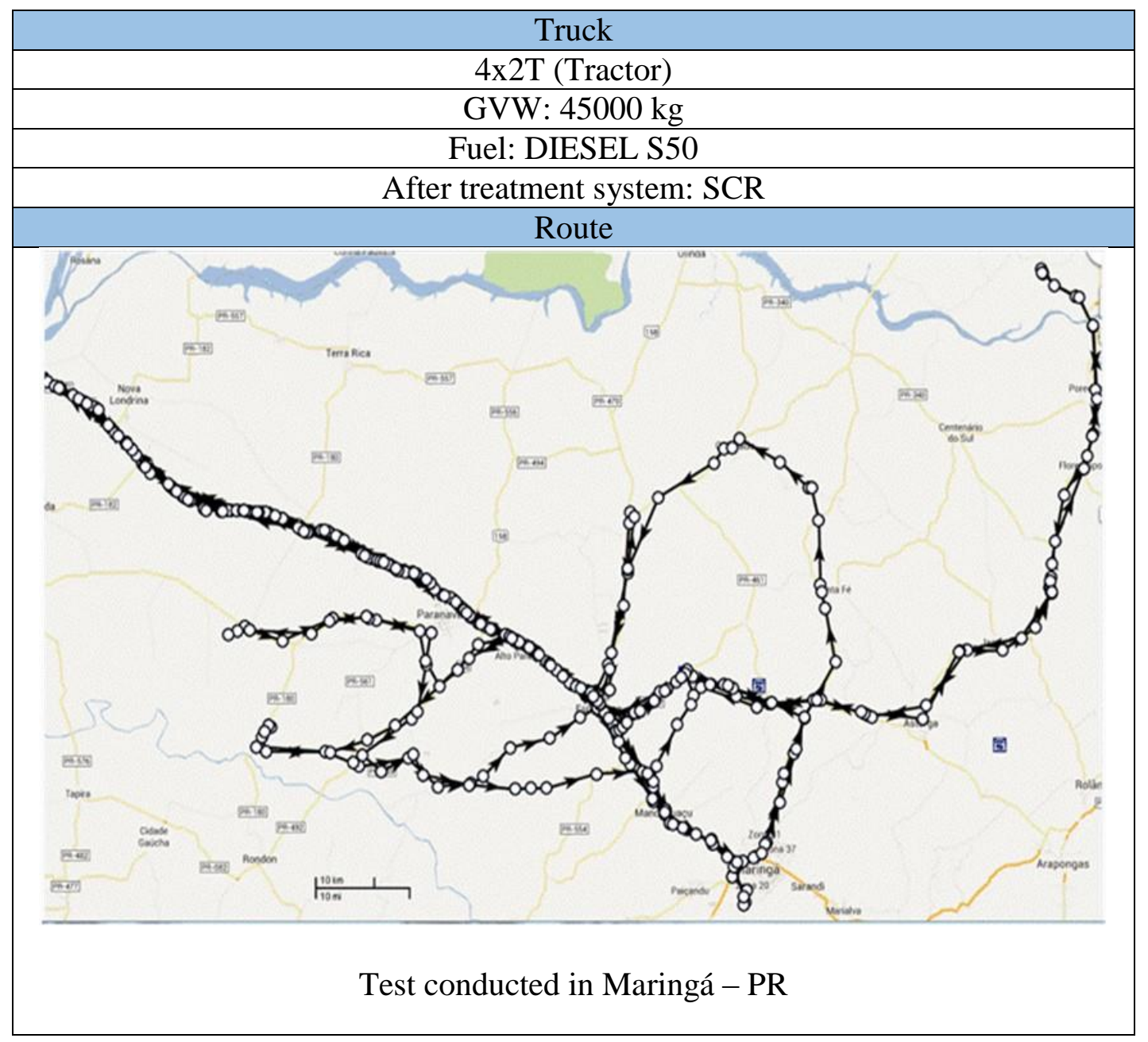

FIGURE 7: Vehicle durability conditions.

\section{RESULTS AND DISCUSSION}

\subsection{Dynamometer test results}

FIG. 8 shows the performance results analyzed throughout the test, as well as the emission of pollutant results before and after the durability test, according to TAB. 4 .

The performance results were evidenced in FIG. 8, which shows the power output of the engine during $2000 \mathrm{~h}$ in dynamometer test. The magnitude remained practically steady throughout the test close to the rated power of the engine $(240 \mathrm{~kW})$. It can be said that neither the components in question (valve and intake seat), nor other components influencing engine performance deteriorated to the point of influencing engine power. 


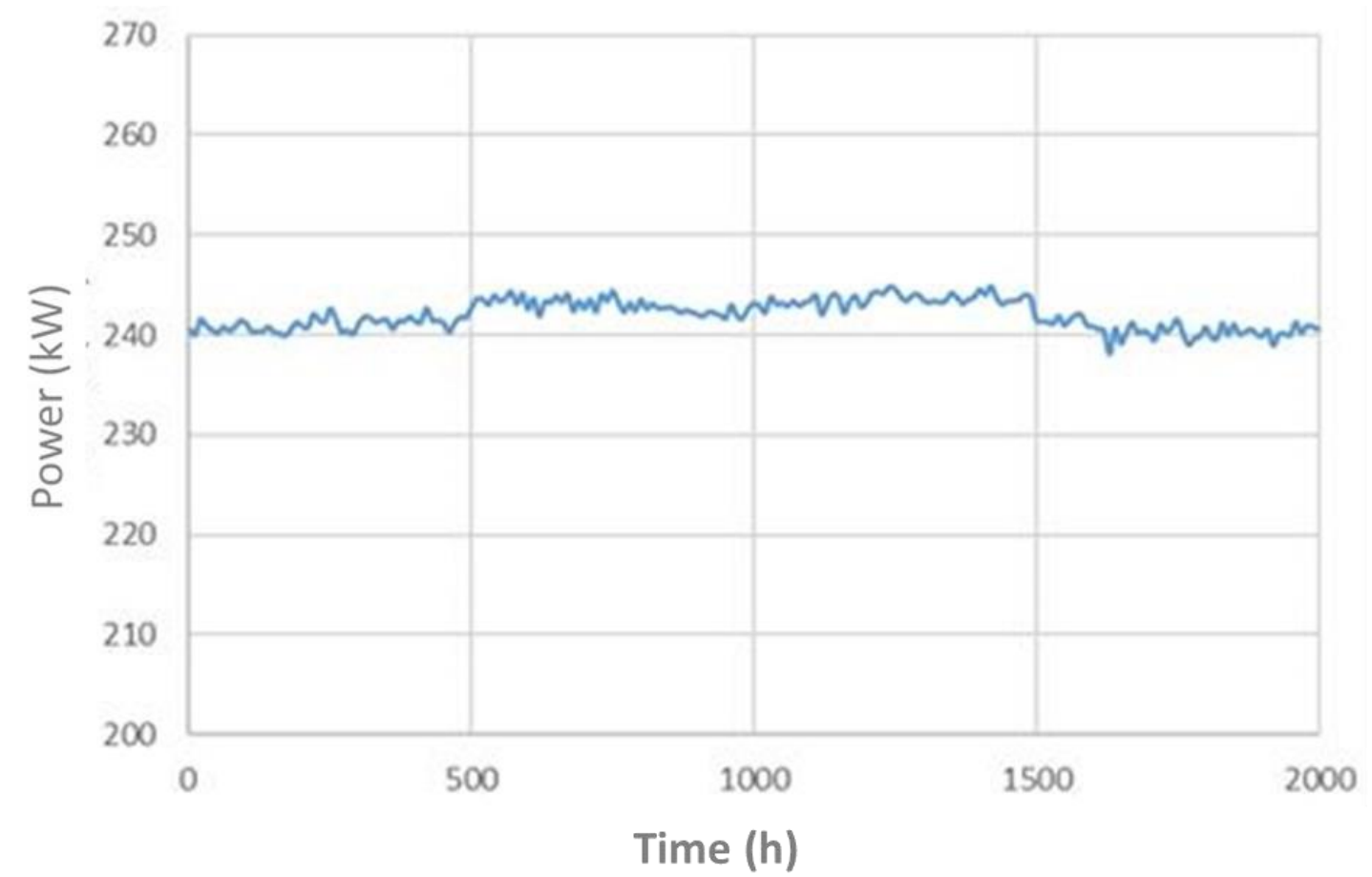

FIGURE 8: Engine performance data (power values during the dynamometer test).

The pollutant emissions were verified before and after the dynamometer durability test and compared with the legal limits, and the results practically did not change between the beginning and the end of the test. As observed in the TAB. 4, the result presented at the end of the test still shows values slightly smaller than the initial ones.

TABLE 4: Comparative results of pollutant emissions according CONAMA resolution phase 7, cycle ESC (European Stationary Cycle) - [10]. Test 1 was conducted before starting the dynamometer test and test 2 after $2000 \mathrm{~h}$ of test. Test results in percentage based on MWM engine reference.

\begin{tabular}{c|l|l|l|l}
\multicolumn{1}{c|}{ Test } & \multicolumn{5}{|c}{ Pollutant emissions (g/kW.h) } \\
\hline & NOx & HC & CO & Particulate material \\
\hline Limit (Resolution) & 2.00 & 0.46 & 1.5 & 0.02 \\
\hline Test 1 (before durability) & $-18.5 \%$ & $0 \%$ & $0 \%$ & $-10 \%$ \\
\hline Test 2 (after durability) & $-26.5 \%$ & $0 \%$ & $0 \%$ & $-20 \%$
\end{tabular}

This part of the results refers to the legal performance requirements of the engine, the power values throughout the test, and the emission of pollutants before and after the dynamometer durability test. These requirements are addressed by ISO 1585 [11] and by CONAMA-PROCONVE P7 [10], respectively. 
At the end of the test, the engine was disassembled and the tribological set of intake valve and valve seat were analyzed. The parts must not present cracks, breaks or excessive wear that would compromise its functionality.

FIG. 9 shows the valve set wear values. The Anderson-Darling statistic was used in a normal probability chart.

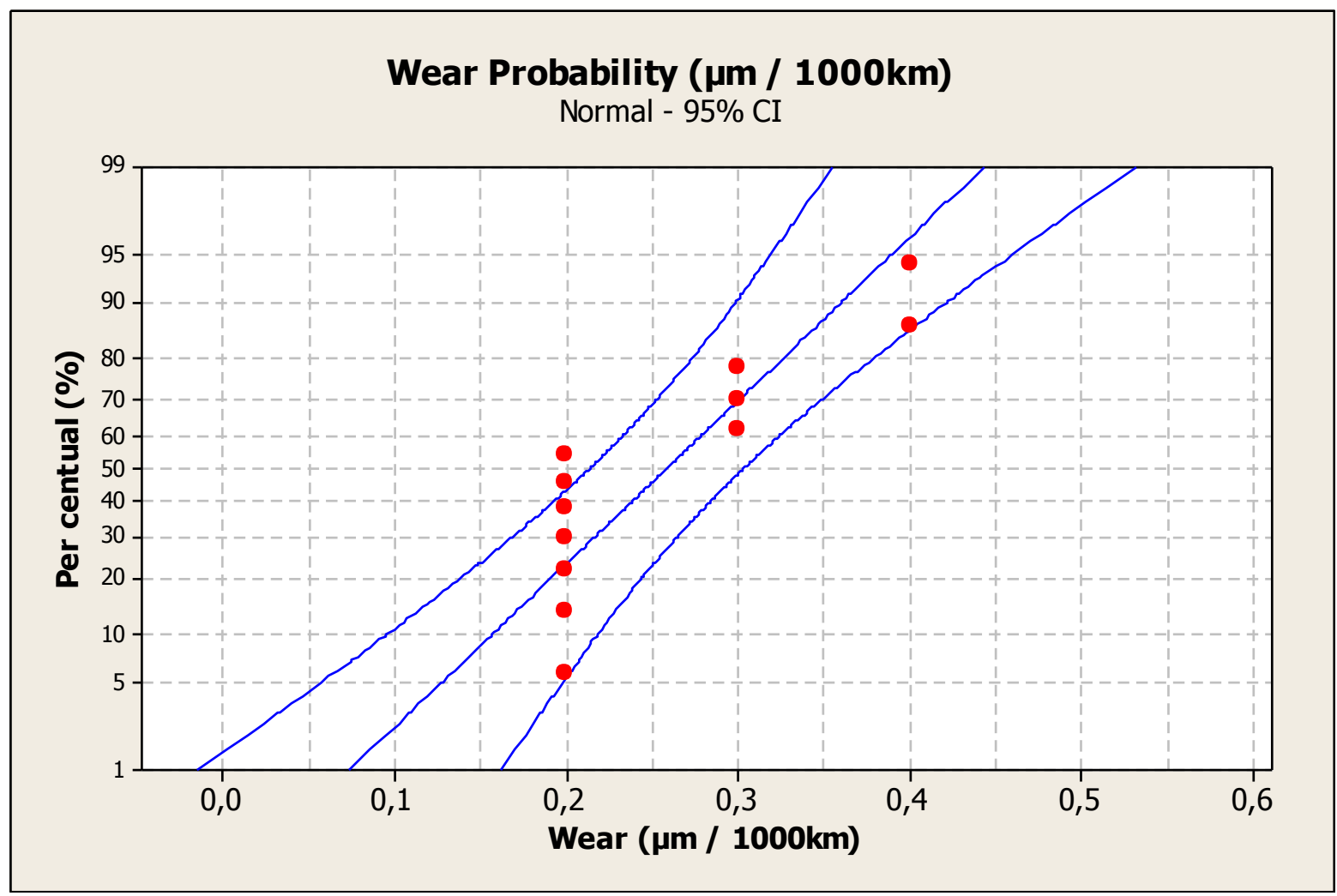

FIGURE 9: Analysis of the wear probability for valve and valve seat assemblies of the durability test (mean values of $0.2583 \mu \mathrm{m}$ per $1000 \mathrm{~km}$ and standard deviation of $0.0793 \mu \mathrm{m}$ per $1000 \mathrm{~km}$ ). Wear of the valve assembly and intake valve seat after 2000 hours test is equivalent to $200,000 \mathrm{~km}$.

Through the scanning electron microscope (SEM), wear on the contact surface between the valve and valve seat was analyzed using images from back-scattered electrons (BSE) and secondary electrons (SEI) and energy dispersive spectroscopy (EDS). FIG. 10 up to 12 show details of the type of wear. 


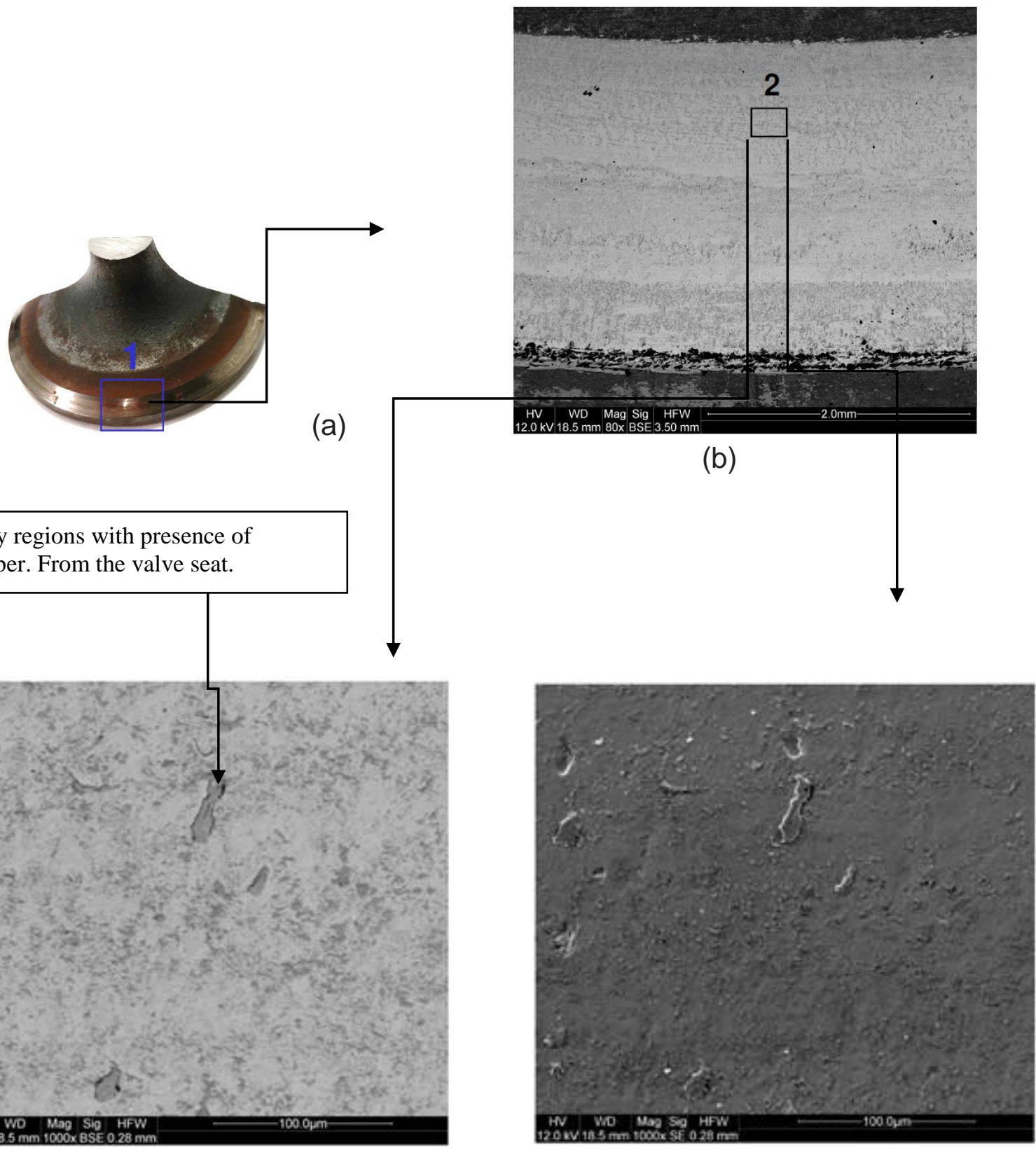

(c)

(d)

FIGURE 10: In (a) valve head detail and point 1 the extended contact region in (b) for surface analysis by SEM performed on the contact surface of the valve with the seat pointed adhesive wear characteristics in (c) BSE analysis and (d) SEI analysis. Adhesive wear is related to high shear stresses caused by friction. 


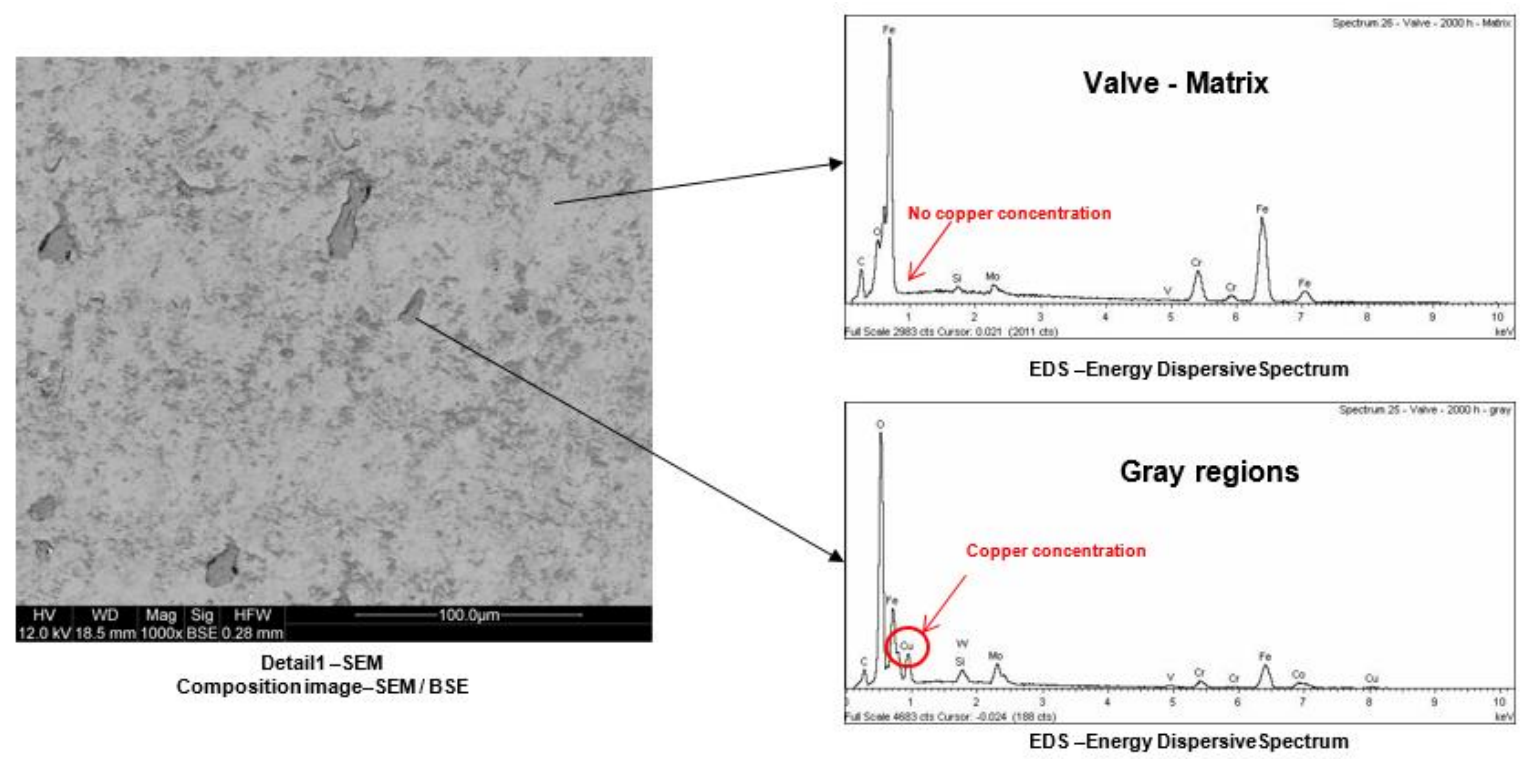

FIGURE 11: SEM / EDS analysis showing the presence of copper.

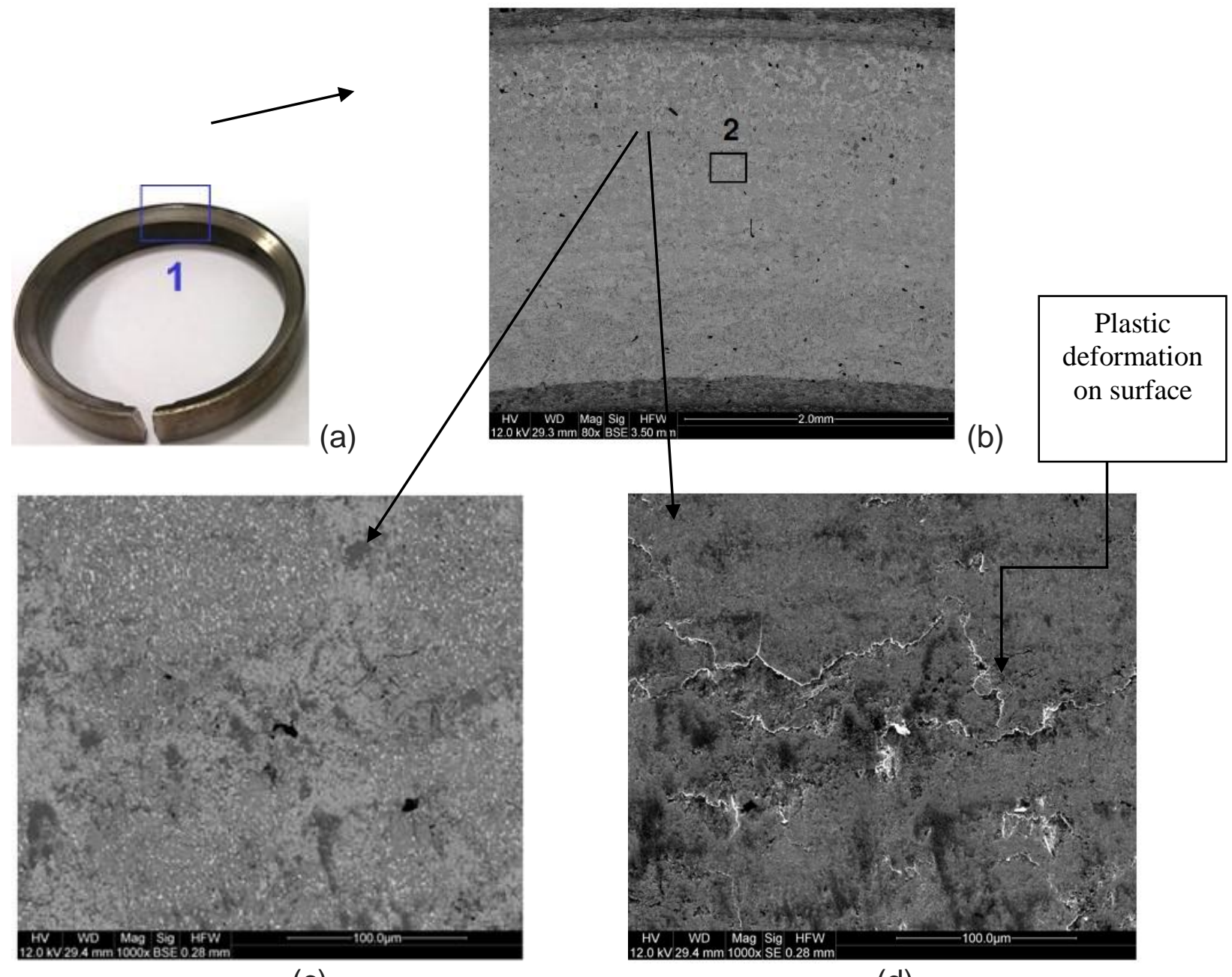

(c)

(d)

FIGURE 12: In (a) detail of the valve seat and point 1 the expanded contact region in (b) for surface analysis by SEM performed on the contact surface with the valve pointed plastic deformation and small detachments of material on the surface in (c) BSE analysis and (d) SEI analysis. 
TAB. 1 shows the level of wear in function of the type of fuel used by the engine. The Diesel cycle engines wear rate in the tribological pair valve and valve seat observed is from $1 \mu \mathrm{m}$ to $5 \mu \mathrm{m}$ for each $1000 \mathrm{~km}$ [1]. The results obtained in both tests, dynamometer and field evaluations, showed values between $0.2 \mu \mathrm{m}$ and $0.4 \mu \mathrm{m}$ for each $1000 \mathrm{~km}$, that is, expressively below the lowest value indicated in the literature.

The engine life requirement tested is $750,000 \mathrm{~km}$. The wear level found in the tests show that when reaching this mileage, the sets of both durability tests would show maximum wear of $0.3 \mathrm{~mm}$. When used, the lowest value quoted in literature that is $1 \mu \mathrm{m}$ for each $1000 \mathrm{~km}$ [1], for the same engine life requirement mileage, it would result in a wear of $0.75 \mathrm{~mm}$, that is, twice more than the result found in practice.

The wear level results show a range of values between $0.2 \mu \mathrm{m}$ to $0.4 \mu \mathrm{m}$ for each $1000 \mathrm{~km}$ run. The variation can be justified by several aspects related to the design, such as dimensional variations in the contact angle between the valve and the valve seat. The contact angle directly influences the deflection of the valve, as well as the contact pressure. Other dimensional aspects such as the run out between the valve seat and the valve guide and between the valve head and the valve stem can also influence the wear of the assembly. It is important to mention the aspect related to the lubrication originated from the lubricating oil flow between valve and valve retainer that affects the wear of the tribological pair, valve and valve seat. Lastly differences in combustion pressures between cylinders can affect wear between valve assemblies and valve seats. However, these cited factors must be analyzed together to understand the differences in wear found.

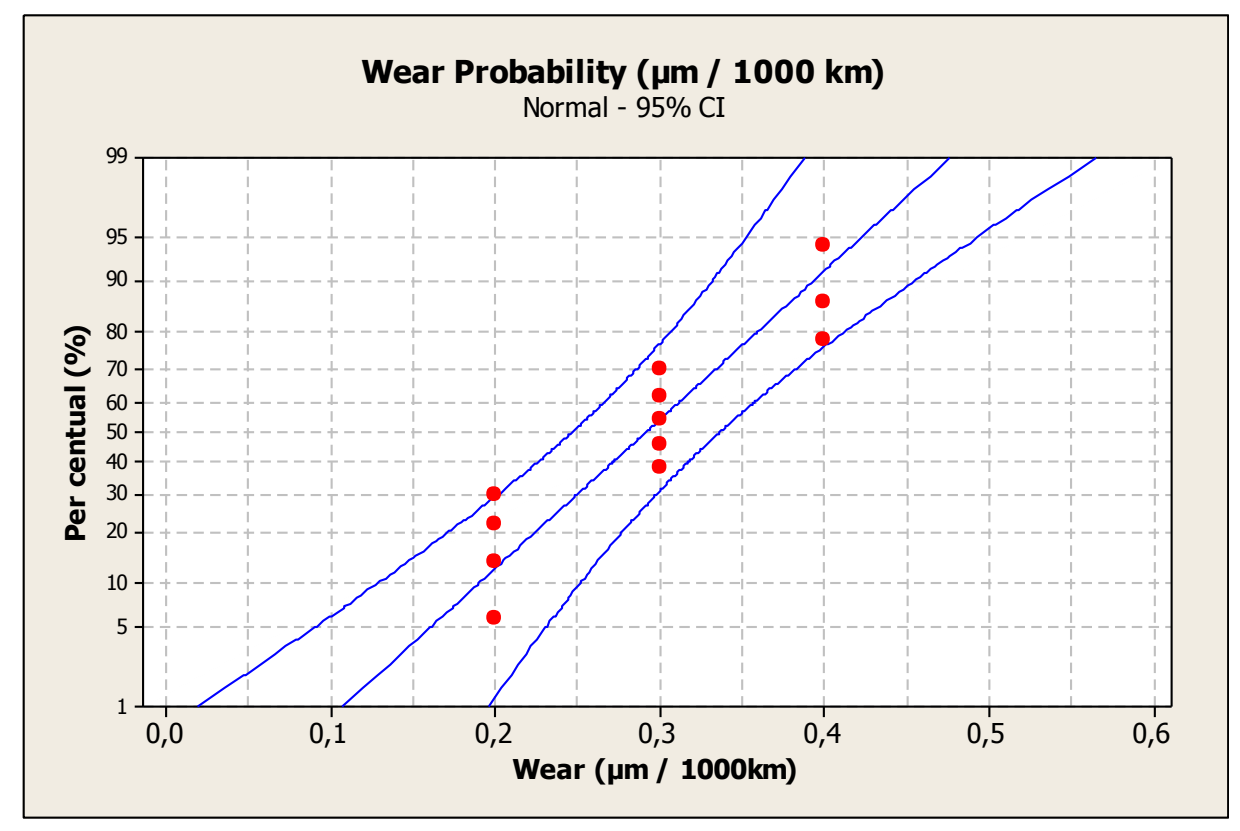

FIGURE 13: Graphical analysis of the wear probability for valve and valve seat assemblies of the vehicle durability test (mean values of $0.2917 \mu \mathrm{m}$ per $1000 \mathrm{~km}$ and standard deviation of $0.0793 \mu \mathrm{m}$ per $1000 \mathrm{~km}$ ). The Anderson-Darling statistic was used in a normal probability chart. 
Through the scanning electron microscope, wear on the contact surface between the valve and valve seat was analyzed using images from back scattered electrons and secondary electrons and dispersive energy spectroscopy. FIG. 14 up to 16 show details of the type of wear.

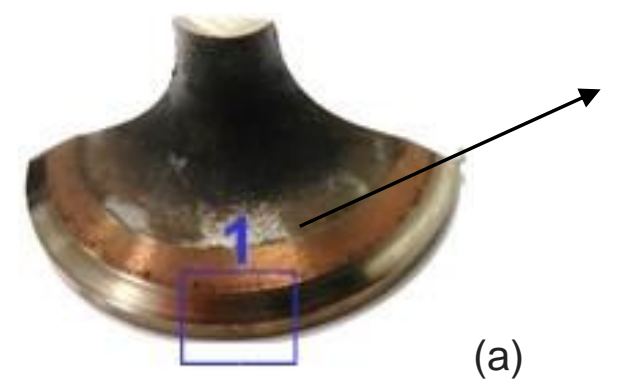

Gray regions with presence of copper. From the valve seat.

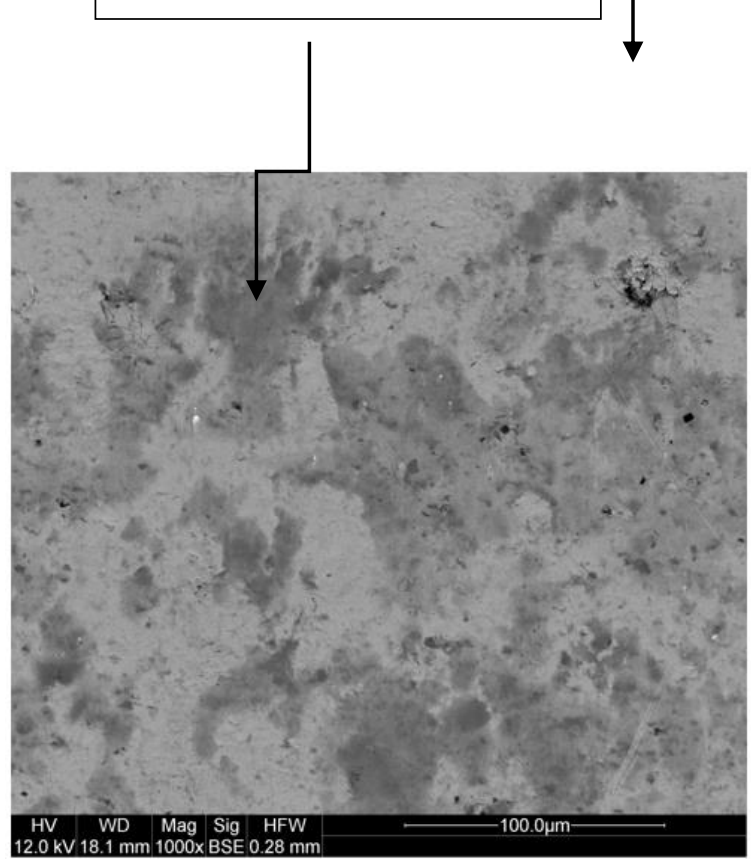

(c)

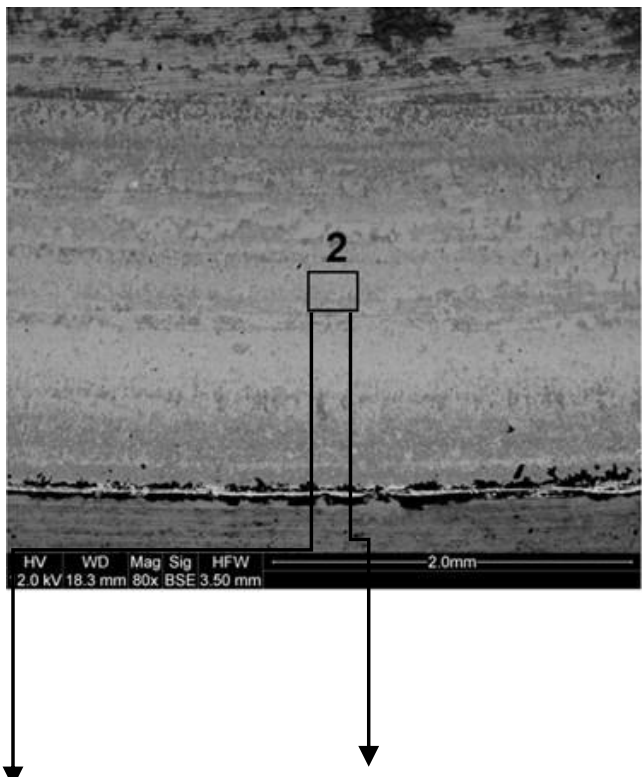

(b)

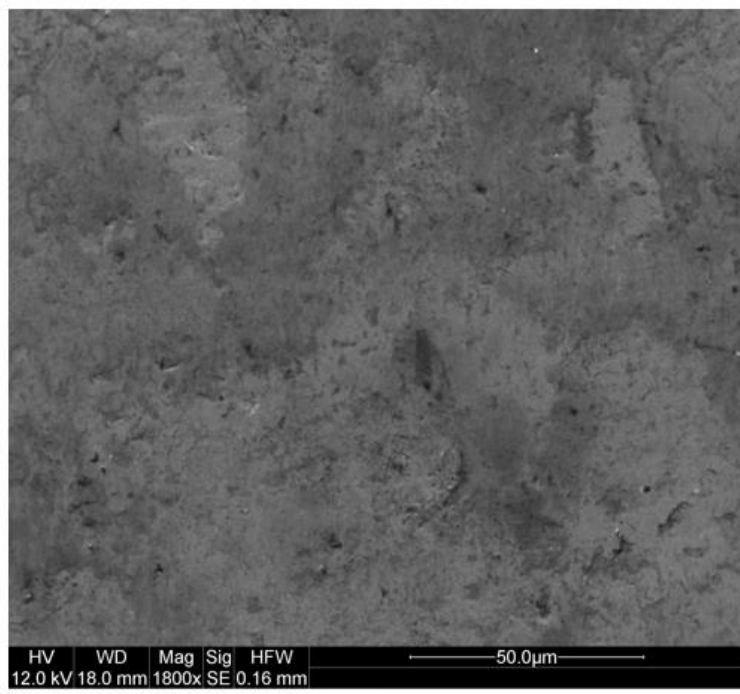

(d)

FIGURE 14: In (a) detail of the valve head and point 1 the expanded contact region in (b) for surface analysis by SEM performed on the contact surface of the valve with the seat pointed adhesive wear characteristics in (c) BSE analysis and (d) SEI analysis. Adhesive wear is related to high shear stresses caused by friction. 


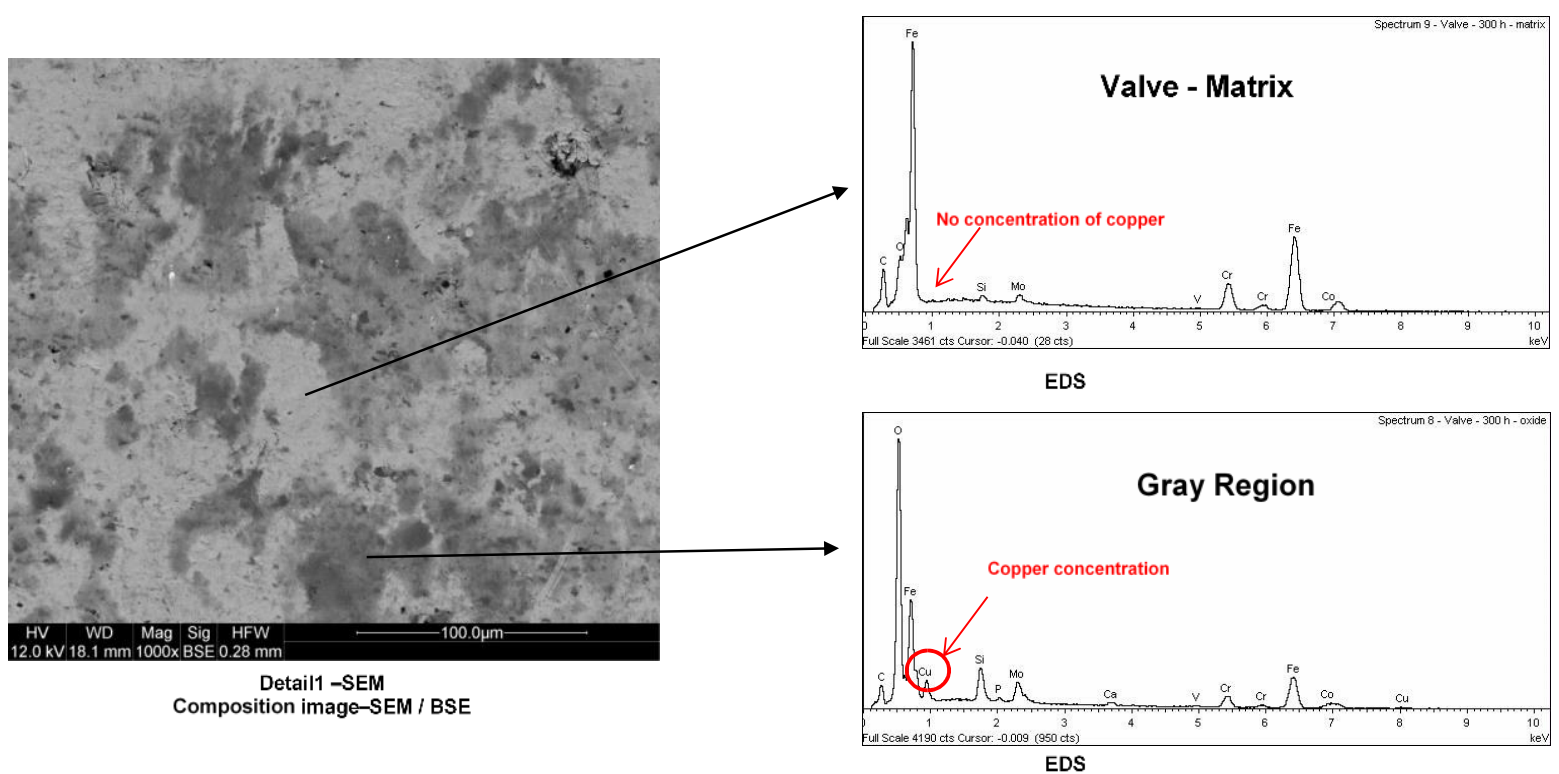

FIGURE 15: SEM / EDS analysis showing the presence of the copper element $(\mathrm{Cu})$ - material transferred from the valve seat to the valve.

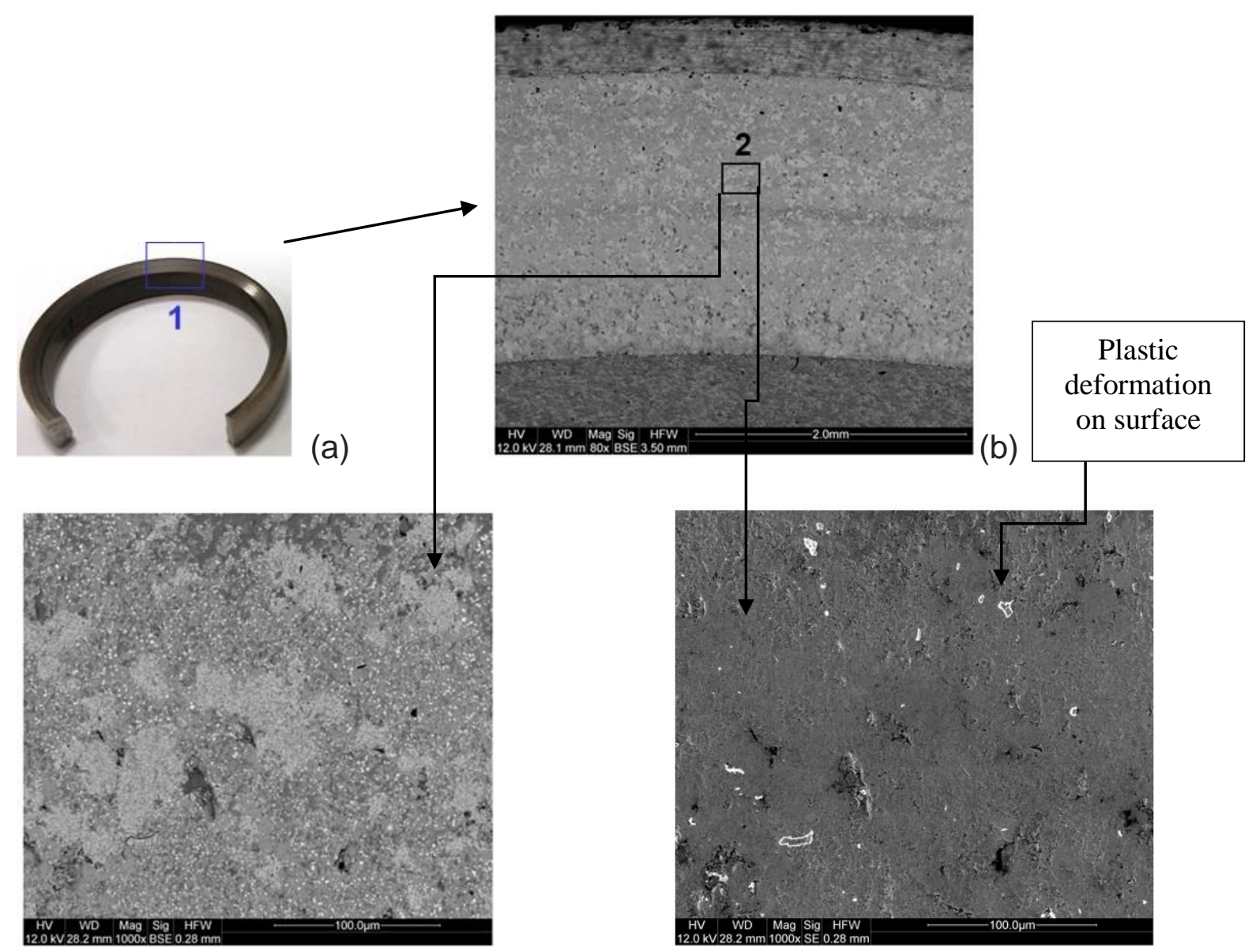

(c)

(d)

FIGURE 16: In (a) detail of the valve seat and point 1 the contact region extended in (b) for surface analysis by SEM performed on the contact surface with the valve pointed plastic deformation and small detachments of material on the surface. In (c) BSE analysis and (d) SEI analysis. 
The wear observed by scanning electron microscopy techniques shows that the same occurred in two ways, being the first one of adhesive wear characteristic, since it was verified the transfer of material from the seat to the valve. In order to achieve this, it is necessary to determine the relationship between the contact of the two surfaces (valve and valve seat), leading to the transfer of material between surfaces or loss of material from any surface. Second was also observed plastic deformation wear at a light level, the definition of plastic deformation as a slip of material due to high contact stress, high surface temperature, high interface friction and inadequate hot hardness [9].

\section{CONCLUSIONS}

The tribological pair, valve and valve seat were submitted to evaluations in real operation condition in dynamometer, controlled laboratory environment, and in vehicle durability tests. In both situations, the set showed excellent performance. This fact is proven by the results obtained both for the legal requirements of performance and emissions of pollutants, as well as for operational requirements related to the life and maintenance of the product. The tribological pair did not show excessive wear that would lead to deterioration of performance during the dynamometer durability test, as well as the emission values of pollutants were stable. The tests conducted on the vehicle showed that the wear levels did not degrade engine life since the wear rates were similar to those found in dynamometer.

There was excellent compatibility between the valve material and the valve seat, the latter component being made from powder metallurgy process, which brings commercial and technical competitive advantages. The technical advantages were evidenced by the results of the wear level obtained in the durability tests, with values below those presented in the literature and that consequently did not increase the emission of pollutants. Concerning the aspect related to the level of wear obtained in the tests, compared to that mentioned in the literature, it can be concluded that the authors should not determine a range of wear values with the type of fuel used. In this way, the information in this literature are references that can be discussed with the practical results of a given engine model.

In view of the practical facts, the tribological pair tested valve and valve seat complied with its basic function, which is the sealing of the combustion chamber to achieve the necessary pressure for combustion. In addition, it did not cause performance deterioration or increased pollutant emissions, as well as meeting extreme work requirements with low wear rates.

\section{REFERENCES}

[1] BASSHUYSEN, Richard; SCHAFER, Fred. Internal combustion engine handbook: basics, components, systems, and perspectives. Local: SAE International, 2004. 
[2] EPMA - EUROPEAN POWDER METALLURGY ASSOCIATION. Powder metallurgy in numbers. Disponível em http://www.epma.com/powder-metallurgy-economic-advantages. Access in: JAN/31/2017.

[3] LAKSHMINARAYANAN, P. A. ; SCHAFER, Fred. NAYAK, Nagaraj S. Critical Component Wear in Heavy Duty Engines. Wiley, 2011.

[4] GEBAUER, K., Performance, tolerance and cost of TiAl passenger car valves. Intermetallics 14, pp. 355-360, 2006.

[5] RADI, Polyana Alves, SANTOS, Lúcia Vieira, BONETTI, Luiz Francisco, AIROLDI, Vladimir J. Trava. TRIBOLOGIA, CONCEITOS E APLICAÇÕES. Anais do $13^{\circ}$ Encontro de Iniciação Científica e Pós-Graduação do ITA. XIII ENCITA, 2007.

[6] JOST, H. P. “Tribology-origin and future”. Wear 136, pp.1-17, 1990.

[7] STACHOWIAK, Gwidon W. e BATCHELOR, Andrew W. Engineering Tribology (4th Edition). Local: Butterworth-Heinemann, 2013.

[8] SEIREG, A. A. Friction and Lubrication in Mechanical Design. Marcel Dekker, 1998.

[9] WANG, Yushu. Introduction to Engine Valvetrains. SAE International, 2007.

[10] Standard CONAMA number 403, 2008.

[11] International Standard ISO 1585 Road vehicles - Engine test code - net power. Third edition, 1992. 